\title{
1 Spike independent replication of human coronavirus in bat cells
}

2

3 Martin Linster, ${ }^{1 * \dagger}$ Marcus G Mah, ${ }^{1 *}$ Dolyce HW Low, ${ }^{1}$ Zhuang Yan, ${ }^{1}$ Jayanthi Jayakumar, ${ }^{1}$

4 Firdaus Samsudin, ${ }^{2}$ Foong Ying Wong, ${ }^{1}$ Peter J Bond, ${ }^{2,3}$ Ian H Mendenhall, ${ }^{1}$ Yvonne CF Su,

5 Gavin JD Smith ${ }^{1,4,5 \dagger}$

6

$7 \quad{ }^{1}$ Programme in Emerging Infectious Diseases, Duke-NUS Medical School, Singapore

$8 \quad{ }^{2}$ Bioinformatics Institute, Agency for Science, Technology, and Research, Singapore

$9 \quad{ }^{3}$ Department of Biological Sciences, National University of Singapore, Singapore

$10 \quad{ }^{4}$ SingHealth Duke-NUS Global Health Institute, SingHealth Duke-NUS Academic Medical

11 Centre, Singapore

$12{ }^{5}$ Duke Global Health Institute, Duke University, United States

$14{ }^{*}$ The authors contributed equally.

15 Corresponding authors.

16

17 Keywords: evolution, pandemic, receptor usage, zoonotic 


\section{Abstract}

19 Bats are a likely zoonotic reservoir for a range of human pathogens including endemic human coronaviruses and SARS-CoV-2. Despite the high burden caused by these viruses, the factors required for the establishment and ongoing transmission in humans are not well understood, hampering efforts for pandemic preparedness. To help understand those adaptations required to cross the species barrier, we serially passaged endemic human coronavirus $229 \mathrm{E}$ isolates in a newly established Rhinolophus (horseshoe bat) kidney cell line. Here we report extensive mutations, including deletions, in the virus genome that result in the loss of spike protein expression, while maintaining the capability to infect bat cells. While we observed a loss of infectivity of human cells for all viruses with spike deletions, one isolate (2613) with an insertion that results in an early stop codon, was recovered from human cells. Deep sequencing of isolate 2613 showed that the majority population had acquired additional nucleotide insertions in the spike resulting in an additional codon that restores spike function.

31 Spike-independent replication of coronaviruses provides an alternative route for infection of

32 host species that don't share common cell-entry receptors.

\section{Introduction}

35 Coronaviruses (CoVs) are positive-sense RNA viruses with genomes ranging from $27 \mathrm{~kb}$ to $3632 \mathrm{~kb}$. CoVs are members of the Coronaviridae family, Orthocoronavirinae subfamily and 37 are divided into four genera, Alphacoronavirus, Betacoronavirus, Deltacoronavirus and 38 Gammacoronavirus ${ }^{1}$. There are four seasonal CoVs, 229E, NL63, OC43 and HKU1, that together account for $10 \%$ to $30 \%$ of upper respiratory tract infections in adults ${ }^{2}$ and circulate globally ${ }^{3}$. To date, three zoonotic coronaviruses have caused epidemics in human populations

41 - SARS-CoV ${ }^{4,5}$, MERS-CoV 6 and SARS-CoV-27 . Based on genetic analyses, all seasonal and 42 zoonotic CoVs have an ancestral origin in bats ${ }^{8}$. Recently, 229E-related bat coronaviruses 
43 have been isolated from bats across central Africa ${ }^{9}$. Temporal analyses of 229E sequences

44 from bats and humans have estimated that 229E diverged from bat ancestors more than 130

45 years ago ${ }^{10}$. The detection of 229E-related viruses in captive alpaca and dromedary suggests

46 that 229E might have transmitted from bats to humans via camelids as intermediate hosts ${ }^{11,12}$

47 Bats harbor a variety of CoVs without displaying obvious disease symptoms ${ }^{13}$.

48 Compared to other mammals, the innate ability of bats to tolerate infection from pathogens

49 has been linked to a loss of genes that trigger inflammation ${ }^{14}$. For CoVs to emerge, they need

50 to overcome the host-species barrier by balancing between conserving and modulating genes

51 while maintaining virus infectivity, replication and spread ${ }^{15}$. One key interaction that enables

$52 \mathrm{CoV}$ entry into host cells is the binding of the spike protein to host receptors. CoVs recognize

various cellular receptors - in humans these comprise: angiotensin-converting enzyme 2

(ACE2) in the case of SARS-CoV ${ }^{16}$, SARS-CoV- $2{ }^{17}$, and NL63 ${ }^{18}$; dipeptidyl peptidase-4 for

MERS-CoV ${ }^{19}$; and aminopeptidase $\mathrm{N}$ for $229 \mathrm{E}^{20}$. It has been hypothesized that

alphacoronaviruses have a higher propensity for zoonotic spillover compared to

betacoronaviruses based on their broader bat host species range and higher frequency of virus jumps between bat genera ${ }^{21}$. To better understand the biology of CoVs in their ancestral bat host, we passaged 229E virus in a kidney cell line derived from Rhinolophus lepidus (Blyth's

60 horseshoe bat).

62 Results

63 Bat cells are susceptible and permissive to $229 E$

64 We first established a Rhinolophus lepidus kidney (Rhileki) cell line to serially passage six

$65229 E$ viruses. Stock viruses were derived from nasopharyngeal swabs, plus a reference strain

66 passaged in human colon adenocarcinoma (Caco2) cells that are denoted $\mathrm{C} 2$ viruses (see

67 Supplementary Fig. 1. for details on passaging and virus nomenclature). During virus 
passaging in Rhileki cells, an increase in viral genomic copies from inoculum to 6 days post inoculation (dpi) was observed, with the exception of viruses at passage one and isolate SG/1197/2010 at all passages (Fig. 1a). The inoculation of Caco2 and Rhileki cells with C2 viruses resulted in infection as detected by nucleocapsid immunofluorescence staining (Supplementary Fig. 2). After ten passages of C2 viruses in Rhileki cells, these C2R10 viruses were inoculated on Caco2 cells, but no signs of infection were observed, with the exception of SG/2613/2011. When titrated on Caco2 cells, C2 virus titers ranged from $6.8 \times 10^{4}$ to $3.2 \times 10^{7} \mathrm{TCID}_{50} / \mathrm{ml}$ but $\mathrm{C} 2 \mathrm{R} 10$ virus titers were below the limit of detection (Fig. 1B). Interestingly, when C2R10 viruses were once more inoculated in Caco2 cells (C2R10C1) only SG/2613/2011 was detectable at a virus titer of $1.8 \times 10^{6} \mathrm{TCID}_{50} / \mathrm{ml}$, whereas all remaining C2R10 isolates were unable to infect Caco2 cells (Fig. 1b). Moreover, when C2 and C2R10 viruses were titrated in Rhileki cells (Fig. 1b), all isolates except SG/1197/2010 yielded a detectable virus titer, although infection of Rhileki cells resulted in low titers throughout. As an additional proof of virus genomic replication, double-stranded RNA was detected at 1 dpi in an immunofluorescent assay (two C2 and C2R10 viruses are shown in

83 Supplementary Fig. 3).

\section{Deletions in the spike and ORF4 genes}

We performed next-generation sequencing (NGS) to determine the patterns of genomic changes that stem from adaptation of 229E viruses to Rhileki cells. Full genomes were recovered for Rhileki passage $1(\mathrm{C} 2 \mathrm{R} 1)$, passage $5(\mathrm{C} 2 \mathrm{R} 5)$ and passage $10(\mathrm{C} 2 \mathrm{R} 10)$ of the six viruses. Remarkably, spike/ORF4 deletions of varying lengths were observed as early as passage 1 in all Rhileki-passaged 229E isolates except SG/2613/2011 (Fig. 2 and

91 Supplementary Fig. 4). These deletions were confirmed by Sanger sequencing with isolate-

92 specific flanking primers (Supplementary Table 1). Critically, the spike deletions either 
remained of constant size or enlarged during passaging. At passage 10 SG/1197/2010,

SG/1340/2010 and TZ/4033K/2017 showed major deletions in the spike and the ORF4.

95 Notably, the spike receptor binding domains (RBDs) were deleted in SG/1197/2010,

96 SG/1340/2010, TZ/4033K/2017, and UK/VR740/1973 C2R10 viruses. Although no deletions

97 were observed for SG/2613/2011 there was a single nucleotide insertion at position 21,069

98 that resulted in a premature stop codon at positions 21,097-21,099. Strikingly, these major

99 genomic changes did not prevent reinfection during serial passage in Rhileki cells, indicating

100 that virus replication was occurring independently of the spike protein.

To understand the potential consequence of these deletions, remaining amino acid

102 positions in $\mathrm{C} 2 \mathrm{R} 10$ viruses were mapped to the 3D structural models of spike and ORF4

103 proteins built using structures of their analogues from SARS-CoV-2 to estimate the positions

104 of deletions and whether protein functions are possibly retained (Supplementary Fig. 5). No

105 remaining function of the spike is expected for all C2R10 viruses with the exception of

106 isolate SG/2326/2011 that retains an intact spike ectodomain. However, the lack of

107 transmembrane (TM) and heptad repeat 2 (HR2) regions that are involved in membrane

108 fusion may impair its function. The function of the ORF4 protein as a viroporin ${ }^{22}$ is expected

109 to be retained in all C2R10 viruses except for SG/1197/2010 which lacks the TM domain and

110 is a slowly growing virus in our cell-based assays.

111 We next compared the frequency of single nucleotide polymorphisms (SNPs) between

112 passages, with SG/1197/2010 excluded due to insufficient coverage (Supplementary Table

113 2). The majority of SNPs (13/21) occurred in the non-structural proteins. With the exception

114 of the deleted regions, bat adapted C2R10 viruses are almost identical to C2 viruses across

115 the remaining genome. There were 17 SNPs that resulted in a non-synonymous mutation, of

116 which four were fixed as the major variant at passage 1, twelve at passage 5 and all 17 at

117 passage 10. Interestingly, two isolates each independently acquired mutations A4854G 
118 (D621G in NSP3) and C25177T (L54F in the membrane protein) and SG/2613/2011 acquired

119 mutation C24200T that resulted in an early stop codon (Q30* in ORF4). NSP3 has been

120 implicated in the formation of molecular pores that span double membrane vesicles as part of 121 coronavirus replication organelle $\mathrm{e}^{23}$.

Spike protein expression during replication in bat cells

124 To understand whether the spike/ORF4 deletions affect subgenomic RNA (sgmRNA)

125 production, we probed for the presence of sgmRNA 2 and 4 specific sequences in $\mathrm{C} 2$ and

126 C2R10 viruses (primers shown in Supplementary Table 1), including the leader-body

127 junctions (LBJ), associated with the production of spike and ORF4 (Fig. 3a and

128 Supplementary Fig. 6a). All C2 viruses produced PCR products of the expected $162 \mathrm{bp}$ or

$129507 \mathrm{bp}$ that corresponded to sgmRNA 2 and 4, respectively (Fig. 3b). In contrast, we

130 observed variation in band sizes among C2R10 viruses, corresponding to the varying sized

131 deletions present in gRNA. Interestingly, a non-canonical LBJ was detected for

$132 \mathrm{SG} / 2326 / 2011$ that begins at nucleotide 23,600 of the spike open-reading frame that encodes sgmRNA X and a related putative ORF (Supplementary Fig. 6b). Analysis of the LBJs and

134 sequences downstream of sgmRNA2 and 4 further confirms the presence of the described deletions and suggests that translation of canonical spike and ORF4 proteins is impaired. To further test the expression of spike protein during passaging of isolates in Rhileki cells, we generated a post-immunization polyclonal rabbit serum directed against the spike protein of 229E. Culture supernatants of C2R1 generally contained little N protein (Fig. 3c), while higher levels of $\mathrm{N}$ were detected in all C2R5 and C2R10 viruses except SG/1197/2010,

140 consistent with viral loads observed during passaging (Fig. 1a). Expression of spike was not

141 detected in all passages in Rhileki cells, except for a faint band observed for SG/2326/2011 at 142 passage 5. 
$144 \quad$ Virus expressing the full spike protein was recovered in human cells

145 To determine if spike independent replication of 229E viruses was specific to Rhileki cells,

146 we inoculated Caco2 cells with C2R10 viruses, termed C2R10C1. Quantitative PCR results

147 were negative except for SG/2613/2011 (data not shown). The culture supernatant of

148 SG/2613/2011 was clearly positive for spike expression in Western blot analysis (Fig. 3c).

149 Detailed examination of the sequencing reads for SG/2613/2011spike, which did not display

150 any deletions, showed virus subpopulations with insertions of one to three nucleotides at

151 position 21,069 across its passage history (Fig. 4a) that resulted in loss and reinstatement of

152 the spike reading frame. The C2R5 virus population had 3 variants, the wild type (GNFY-

$153 \mathrm{NE})$, the majority variant (GNFL-Q*) with a $1 \mathrm{nt}$ insertion resulting in a stop at positions

154 21,097-21,099, and a final variant (GNFFIAL*) with 2 nt insertions and a stop at position

$15521,078-21,080$. The wild type was not detected in C2R10, possibly due to low sequencing

156 coverage. In C2R10C1, passaged in Caco2 cells, both the wild type (GNFY-NE) and a new

157 variant (GNFFY-NE) with a 3 nt insertion that recovers the spike reading frame were

158 present, consistent with the observed expression of spike (Fig. 3c), reiterating that spike is

159 essential for efficient virus infection of human cells.

160

\section{Discussion}

162 To our knowledge this is the first report of active replication of coronaviruses without the

163 required spike receptor binding. The spike gene, especially the RBD is highly variable with

164 multiple insertions and deletions observed ${ }^{24}$. Spike deletion variants have been documented

165 in fatal human cases of MERS-CoV and SARS-CoV-2 and were attributed to immune driven

166 antibody escape ${ }^{25,26}$. While some bat sarbecoviruses bind human ACE2, most are unable to

167 engage this receptor due to variation or deletions within the RBD, suggesting alternative 
receptors or cellular entry pathways ${ }^{27-29}$. Recent studies have revealed detail of coronavirus replication including the description of large virus-containing vesicles (LVCVs) containing intact $^{30,31}$ or spike-less virions ${ }^{32}$, that might help to explain our observed spike-independent

171 virus maintenance in Rhileki cells. Alternative pathways for egress of virions, possibly as

172 part of LVCVs, subsequent attachment and internalization without a strict receptor requirement have also been elucidated ${ }^{33,34}$. utilize receptor independent membrane fusion. This mechanism may not be found in all bat tissues or species but could help explain features of infection in bats such as low levels of

177 viraemia ${ }^{35}$ and the dampened immune response to highly pathogenic viruses ${ }^{36}$. However, it is unlikely that the full spike gene deletions would be present during natural infection as spike binding would obviously increase virus fitness in the presence of the appropriate receptor, and the vast majority of natural spike proteins are full length. Rather, the infection dynamics in Rhileki cells likely favored replication of a shorter viral genome in the absence of other selection pressures present in a natural setting. without requiring the spike protein could provide an alternative route for infection between different bat species, and possibly other hosts, which may not share common receptors. In this scenario, upon transmission to a new host species, infection could be initiated by macropinocytosis of shed virions within LVCVs in urine or stool, but would be significantly increased by acquiring a matching receptor binding protein either from recombination with the host or other coronaviruses. It is therefore critical that we gain a better understanding of the infection biology of host species, particularly the role of LVCVs, involved in the emergence of zoonotic coronaviruses. 


\section{Methods}

Establishment of the Rhileki cell line

195 Kidney tissue of a Rhinolophus lepidus bat (NUS-IACUC B01/12) were processed into

196 cellular mixtures by mechanical disruption through a $100 \mu \mathrm{m}$ cell strainer. One-hundred

197 thousand cells were plated in a T-25 Corning CellBIND flask containing maintenance media

198 (RPMI with L-glutamine, 10\% FBS, 2.5\% HEPES, 1x antibiotics-antimycotics) at $37^{\circ} \mathrm{C}, 5 \%$

$199 \mathrm{CO}_{2}$ for expansion. Cells were then serially diluted in 384-well plates. Wells containing

200 single cell patches were selected, trypsinized and serially diluted additional two times before

201 expansion. A spontaneously immortalized clonal cell line was selected and named Rhileki for

202 Rhinolophus lepidus kidney which is currently maintained until passage 30.

203

204

Viruses

205

Isolates SG/1197/2010, SG/1340/2010, SG/2326/2011, SG/2613/2011 were obtained from a study in Singapore ${ }^{38}$. Isolate TZ/4033K/2017 was obtained from a study conducted in

Tanzania (unpublished). UK/VR740/1973 was procured from the American Type Culture

Collection (ATCC). All viruses were cultured for 3 days in Caco2 cells (ATCC, HTB-37) at

$33{ }^{\circ} \mathrm{C}$ in Dulbecco's Modified Eagle Medium GlutaMAX containing 3\% fetal bovine serum

(FBS) and 1\% penicillin-streptomycin. Viruses were titrated for 5 days in a 96-well format,

211 plates were fixed with 100\% methanol, blocked with 3\% bovine serum albumin (BSA),

212 stained with 1E7 primary monoclonal antibody (Eurofins Technologies Ingenasa) binding to

213 the 229E nucleocapsid protein and a goat anti-mouse secondary antibody conjugated with

214 fluorescein isothiocyanate (Abcam, ab6785). TCID 50 titers were calculated according to the

215 method of Reed and Muench ${ }^{39}$.

217 Serial virus passage 
218 Rhileki cells were seeded at a density of $2 \times 10^{6}$ in T25 flasks. The virus inoculum at MOI

2190.01 was incubated at $33^{\circ} \mathrm{C}$ for 2 hours. The inoculum was removed, cells washed once with

220 phosphate buffered saline (PBS) and medium was replenished (DMEM, 1\% sodium pyruvate,

$2211 \%$ non-essential amino acids, and $0.5 \%$ BSA). Supernatant was collected at time points 0,3 ,

2226,9 dpi. On 9 dpi, the cells were scraped, pelleted and stored at $-80^{\circ} \mathrm{C}$. For virus passages,

223 viral genome copies in the supernatant of 6 dpi were adjusted to contain $10^{5}$ to $10^{6}$ genome

224 equivalents in the subsequent inoculum.

225

226 Double-stranded RNA staining

227 Caco2 and Rhileki cells were seeded into 2-well chambered coverglass on the day before

228 infection. Caco2 and Rhileki cells were infected with C2 or C2R10 viruses respectively for 2

229 hours at $33{ }^{\circ} \mathrm{C}$. Cells were fixed and permeabilized at 1 dpi and stained with $\mathrm{J} 2$ antibody that

230 detects for double-stranded RNA complexes.

$232 \quad$ RNA extraction and viral genome copy analysis

233 Briefly, total RNA was extracted from $150 \mu 1$ of supernatant collected at all time points using

234 the Direct-zol RNA MiniPrep kit (Zymo Research) according to the manufacturer's

235 instructions. Samples were analyzed by real-time quantitative reverse-transcription-PCR (RT-

236 qPCR) using primers specific for 229E nucleocapsid as described previously ${ }^{40}$. Nucleocapsid

237 sequences were cloned and cycle threshold values were converted into viral genome copies

238 per microliter based on regression analysis of plasmid dilutions.

$240 \quad$ Whole genome sequencing and genetic analysis

241 Complementary DNA libraries of passage 1, 5 and 10 were constructed using TruSeq RNA

242 Library Prep Kit (Illumina) according to the manufacturer's instruction. The quality of the 
libraries was verified using the RNA bioanalyzer (Agilent Technologies) and normalized

244 using the KAPA Library Prep Kit (Roche). The libraries were sequenced using a 250 bp flow

245 cell on the Illumina MiSeq System. Raw NGS reads were trimmed by Trimmomatic v0.39 to

246 remove adaptors and low-quality reads ${ }^{41}$. In order to obtain consensus sequences, C2 virus

247 consensus of each isolate was used as reference to assemble trimmed and raw reads using the

248 BWA-MEM algorithm in UGENE v.34 ${ }^{42}$. Coverage, depth and statistics of the assembled

249 reads were visualized in Geneious R9.1.8 and Integrative Genomics Viewer ${ }^{43}$. Consensus

250 sequences were aligned using MAFFT v7.222 and annotated in Geneious R9.1.8.

Sanger deletion verification

253 Trimmed and untrimmed reads were compared to flag deleted regions in the genome. To confirm the deletions, flanking primers were designed (Supplementary Table 1). Using isolate specific primers, cDNA synthesis was performed using Superscript III First-Strand Synthesis System (ThermoFisher Scientific). This was followed by PCR, of which a $50 \mu 1$ mixture consisted cDNA, sense/anti-sense primers $(10 \mu \mathrm{M}), 10 \mathrm{x}$ Pfu reaction buffer and DNA polymerase (Promega) and $10 \mathrm{mM}$ dNTP mix (ThermoFisher Scientific). The PCR was conducted at $95{ }^{\circ} \mathrm{C}$ for 2 mins, 35 cycles at $95^{\circ} \mathrm{C}$ for $1 \mathrm{~min}, 47^{\circ} \mathrm{C}$ for $30 \mathrm{secs}, 72{ }^{\circ} \mathrm{C}$ for 2 mins and final extension at $72{ }^{\circ} \mathrm{C}$ for 5 mins. PCR products were visualized using a $1.5 \%$ gel and sequences confirmed by Sanger sequencing (Macrogen).

Subgenomic mRNA leader-body junction for sgmRNA 2 and 4

264 As part of the replication cycle of $\mathrm{CoVs}$, translation of structural proteins is preceded by

265 discontinuous transcription of subgenomic RNA (sgRNA) ${ }^{45}$, whereby nested species of 266 subgenomic messenger RNA (sgmRNA) are produced. Structural proteins of 229E are

267 translated from sgmRNA 2, 4, 5, 6, 7, while sgmRNA 3 is truncated and was described to be 
non-functional ${ }^{46-48}$. The leader-body junction consists of nucleotides within the transcription-

271 formation of sgmRNA which can be distinguished based on their sequence from the genomic

272 RNA (gRNA). Reverse primers specific for the spike (226R) and ORF4 (617R) genes were designed to synthesize cDNA from total RNA extracted from infected cell lysates. Using a semi-nested PCR approach, the 2F primer targeting the start of the leader RNA was used in combination with $158 \mathrm{R}$, and subsequently with $87 \mathrm{R}$ to generate $\mathrm{PCR}$ products that contain

276 the leader RNA, leader-body junction and a portion of sgmRNA 2. Similarly, to test the presence of sgmRNA 4, 2F was employed together with primers 520R and 397R. PCR products were visualized on a $1.5 \%$ agarose gel.

\section{$\underline{\text { Western blot }}$}

281 Supernatant harvested from infected Rhileki cells were centrifuged at 3,500 rpm and

282 precipitated with $10 \%$ polyethylene glycol 8000 overnight in $4{ }^{\circ} \mathrm{C}$. The solution was centrifuged at $12,000 \mathrm{rpm}$ for 1 hour at $4{ }^{\circ} \mathrm{C}$ and pellet resuspended in NTE buffer $(1 \mathrm{M} \mathrm{NaCl}$, $1 \mathrm{M}$ Tris- $\mathrm{HCl} \mathrm{pH} 8.0,0.5 \mathrm{M}$ EDTA $\mathrm{pH} 8.0$ ). The suspension was subjected to a $20 \%$ sucrose cushion via ultracentrifugation using a SW41 rotor at $32,000 \mathrm{rpm}$ for 2 hours at $4{ }^{\circ} \mathrm{C}$. The pellet was resuspended in NTE buffer and reduced with 5x lane marker reducing sample buffer (ThermoFisher Scientific) at $95{ }^{\circ} \mathrm{C}$ for 10 minutes. Purified virions were separated down a 4 - 20\% Mini-PROTEAN TGX stain-free protein gel (Bio-Rad Laboratories) at 90 volts for 90 minutes. The gel was then transferred onto a polyvinylidene fluoride membrane and blocked with 5\% BSA at room temperature for 1 hour. This was followed by overnight

291 probing with primary antibody at $4{ }^{\circ} \mathrm{C}$ and 1 hour with either anti-mouse or -rabbit

292 horseradish peroxidase-linked IgG secondary antibodies. Blots were visualized using a CCD 
imager detector (Bio-Rad Laboratories) after ECL detection (Amersham Biosciences). The

294 primary antibodies include mouse monoclonal antibody $1 \mathrm{E} 7$ which is anti-229E nucleocapsid

295 protein and polyclonal rabbit sera derived from immunization of rabbits with 229E spike

296 protein (GenScript).

297

298

\section{Protein modelling}

299 The full genomic sequences of human coronavirus 229E C2R10 isolates were translated to

300 amino acid sequences using the Expasy Translate webserver

301 (https://web.expasy.org/translate/) ${ }^{49}$ in all three forward 5' to 3' reading frames. These amino

302 acid sequences were then aligned to the full-length sequences of 229E S and ORF4 proteins

303 obtained from GenBank (accession number: NC_002645) using Clustal Omega webserver

304 (https://www.ebi.ac.uk/Tools/msa/clustalo/ $)^{50}$ to determine reading frames corresponding to

305 each protein and deleted residues. The full-length structural models of human coronavirus

306 229E S protein was built using the SARS-CoV-2 S protein model as the template ${ }^{51}$. Modeller

307 version $9.21^{52}$ was used to generate ten homology models and the best model was selected

308 based on having the lowest discreet optimized protein energy ${ }^{53}$, while minimizing

309 Ramachandran outliers ${ }^{54}$. Using similar protocols, the ORF4 protein model was built using

310 the cryo-EM structure of SARS-CoV-2 ORF3a ion channel (PDB: 7KJR) ${ }^{55}$ as the template.

311 The N- and C-terminal regions were unresolved and therefore modelled as unstructured

312 loops. Deleted regions of the C2R10 isolates were mapped to these structures and visualized

313 with $\mathrm{VMD}^{56}$.

\section{Reporting summary}

316 Further information on research design is available in the Nature Research Reporting

317 Summary linked to this paper. 


\section{Data availability}

320 Data that support the findings of this study have been deposited in GenBank with accession

321 numbers XXXX and the SRA database under BioProject accession number XXXX.

\section{References}

1. Gorbalenya, A. E. et al. The species Severe acute respiratory syndrome-related coronavirus: classifying 2019-nCoV and naming it SARS-CoV-2. Nat. Microbiol. 5, 536544. Link: https://go. nature. com/3cW9qJR (2020).

2. Paules, C. I., Marston, H. D. \& Fauci, A. S. Coronavirus Infections-More Than Just the Common Cold. JAMA 323, 707-708 (2020).

3. Nickbakhsh, S. et al. Epidemiology of Seasonal Coronaviruses: Establishing the Context for the Emergence of Coronavirus Disease 2019. J Infect Dis 222, 17-25 (2020).

4. Peiris, J. S. M. et al. Coronavirus as a possible cause of severe acute respiratory syndrome. Lancet 361, 1319-1325 (2003).

333 5. Ksiazek, T. G. et al. A novel coronavirus associated with severe acute respiratory $334 \quad$ syndrome. $N$ Engl J Med 348, 1953-1966 (2003).

335 6. Zaki, A. M., van Boheemen, S., Bestebroer, T. M., Osterhaus, A. D. M. E. \& Fouchier, R.

336 A. M. Isolation of a novel coronavirus from a man with pneumonia in Saudi Arabia. $N$

$337 \quad$ Engl J Med 367, 1814-1820 (2012).

338 7. Zhu, N. et al. A Novel Coronavirus from Patients with Pneumonia in China, 2019. N Engl

$339 \quad J$ Med 382, 727-733 (2020).

340 8. Forni, D., Cagliani, R., Clerici, M. \& Sironi, M. Molecular Evolution of Human

341 Coronavirus Genomes. Trends Microbiol 25, 35-48 (2017). 
9. Pfefferle, S. et al. Distant Relatives of Severe Acute Respiratory Syndrome Coronavirus and Close Relatives of Human Coronavirus 229E in Bats, Ghana. Emerg Infect Dis 15, 1377-1384 (2009).

10. Lau, S. K. P. et al. Molecular Evolution of Human Coronavirus 229E in Hong Kong and a Fatal COVID-19 Case Involving Coinfection with a Novel Human Coronavirus 229E Genogroup. mSphere 6, e00819-20 (2021). Human Coronavirus 229E. Viruses 4, 3689-3700 (2012).

12. Sabir, J. S. M. et al. Co-circulation of three camel coronavirus species and recombination of MERS-CoVs in Saudi Arabia. Science 351, 81-84 (2016). 81, 4012-4020 (2007).

14. Ahn, M. et al. Dampened NLRP3-mediated inflammation in bats and implications for a special viral reservoir host. Nat Microbiol 4, 789-799 (2019).

15. Menachery, V. D., Graham, R. L. \& Baric, R. S. Jumping species-a mechanism for coronavirus persistence and survival. Curr Opin Virol 23, 1-7 (2017).

16. Li, W. et al. Angiotensin-converting enzyme 2 is a functional receptor for the SARS coronavirus. Nature 426, 450-454 (2003).

361 17. Hoffmann, M. et al. SARS-CoV-2 Cell Entry Depends on ACE2 and TMPRSS2 and 362 Is Blocked by a Clinically Proven Protease Inhibitor. Cell 181, 271-280.e8 (2020).

363 18. Hofmann, H. et al. Human coronavirus NL63 employs the severe acute respiratory 364 syndrome coronavirus receptor for cellular entry. Proc Natl Acad Sci U S A 102, 79887993 (2005). 
366 19. Raj, V. S. et al. Dipeptidyl peptidase 4 is a functional receptor for the emerging

367 human coronavirus-EMC. Nature 495, 251-254 (2013).

368 20. Yeager, C. L. et al. Human aminopeptidase $\mathrm{N}$ is a receptor for human coronavirus

369 229E. Nature 357, 420-422 (1992).

370 21. Latinne, A. et al. Origin and cross-species transmission of bat coronaviruses in China.

Nat Commun 11, 4235 (2020).

372

22. Zhang, R. et al. The ORF4a protein of human coronavirus 229E functions as a

viroporin that regulates viral production. Biochim Biophys Acta 1838, 1088-1095 (2014).

23. Wolff, G. et al. A molecular pore spans the double membrane of the coronavirus replication organelle. Science 369, 1395-1398 (2020).

24. Li, Z. et al. The human coronavirus HCoV-229E S-protein structure and receptor binding. Elife 8, e51230 (2019).

25. Lu, X. et al. Spike gene deletion quasispecies in serum of patient with acute MERSCoV infection. J Med Virol 89, 542-545 (2017).

380 26. McCarthy, K. R. et al. Recurrent deletions in the SARS-CoV-2 spike glycoprotein drive antibody escape. Science 371, 1139-1142 (2021).

27. Letko, M., Marzi, A. \& Munster, V. Functional assessment of cell entry and receptor $(2020)$.

28. Wells, H. L. et al. The evolutionary history of ACE2 usage within the coronavirus subgenus Sarbecovirus. Virus Evol 7, veab007 (2021).

29. Ren, W. et al. Difference in receptor usage between severe acute respiratory 1907 (2008) 
30. Snijder, E. J. et al. A unifying structural and functional model of the coronavirus replication organelle: Tracking down RNA synthesis. PLoS Biol 18, e3000715 (2020).

392 31. Klein, S. et al. SARS-CoV-2 structure and replication characterized by in situ cryo393 electron tomography. Nat Commun 11, 5885 (2020).

394 32. Mendonça, L. et al. Correlative multi-scale cryo-imaging unveils SARS-CoV-2 assembly and egress. Nat Commun 12, 4629 (2021).

396 33. Ghosh, S. et al. $\beta$-Coronaviruses Use Lysosomes for Egress Instead of the

397 Biosynthetic Secretory Pathway. Cell 183, 1520-1535.e14 (2020).

398 34. Freeman, M. C., Peek, C. T., Becker, M. M., Smith, E. C. \& Denison, M. R.

399 Coronaviruses induce entry-independent, continuous macropinocytosis. mBio 5, e01340$400 \quad 01314(2014)$.

401 35. Plowright, R. K. et al. Ecological dynamics of emerging bat virus spillover. Proc Biol Sci 282, $20142124(2015)$.

403 36. Goh, G. et al. Complementary regulation of caspase-1 and IL-1 $\beta$ reveals additional 404 mechanisms of dampened inflammation in bats. Proc Natl Acad Sci U S A 117, 28939$405 \quad 28949(2020)$.

406 37. Zhou, P. et al. Fatal swine acute diarrhoea syndrome caused by an HKU2-related $407 \quad$ coronavirus of bat origin. Nature 556, 255-258 (2018).

408 38. Low, J. G. H. et al. Early Dengue infection and outcome study (EDEN) - study design 409 and preliminary findings. Ann Acad Med Singap 35, 783-789 (2006).

410 39. Reed, L. J. \& Muench, H. A Simple Method of Estimating Fifty Per Cent Endpoints. 411 American Journal of Epidemiology 27, 493-497 (1938).

412 40. Hoek, R. A. S. et al. Incidence of viral respiratory pathogens causing exacerbations in 413 adult cystic fibrosis patients. Scand J Infect Dis 45, 65-69 (2013). 
414 41. Bolger, A. M., Lohse, M. \& Usadel, B. Trimmomatic: a flexible trimmer for Illumina 415 sequence data. Bioinformatics 30, 2114-2120 (2014).

416 42. Okonechnikov, K., Golosova, O., Fursov, M., \& UGENE team. Unipro UGENE: a 417 unified bioinformatics toolkit. Bioinformatics 28, 1166-1167 (2012).

418 43. Robinson, J. T. et al. Integrative Genomics Viewer. Nat Biotechnol 29, 24-26 (2011).

419 44. Katoh, K., Misawa, K., Kuma, K. \& Miyata, T. MAFFT: a novel method for rapid 420 multiple sequence alignment based on fast Fourier transform. Nucleic Acids Res 30, 3059$4213066(2002)$.

422 45. Pasternak, A. O., Spaan, W. J. M. \& Snijder, E. J. Nidovirus transcription: how to 423 make sense...? J Gen Virol 87, 1403-1421 (2006).

424 46. Viehweger, A. et al. Direct RNA nanopore sequencing of full-length coronavirus 425 genomes provides novel insights into structural variants and enables modification analysis. Genome Res 29, 1545-1554 (2019).

47. Schreiber, S. S., Kamahora, T. \& Lai, M. M. Sequence analysis of the nucleocapsid protein gene of human coronavirus 229E. Virology 169, 142-151 (1989).

48. Raabe, T., Schelle-Prinz, B. \& Siddell, S. G. Nucleotide sequence of the gene encoding the spike glycoprotein of human coronavirus HCV 229E. J Gen Virol 71 ( Pt 5), 1065-1073 (1990).

49. Gasteiger, E. et al. ExPASy: The proteomics server for in-depth protein knowledge and analysis. Nucleic Acids Res 31, 3784-3788 (2003).

434 50. Sievers, F. et al. Fast, scalable generation of high-quality protein multiple sequence alignments using Clustal Omega. Mol Syst Biol 7, 539 (2011).

436 51. Raghuvamsi, P. V. et al. SARS-CoV-2 S protein:ACE2 interaction reveals novel 437 allosteric targets. Elife 10, e63646 (2021). 
438 52. Sali, A. \& Blundell, T. L. Comparative protein modelling by satisfaction of spatial 439 restraints. J Mol Biol 234, 779-815 (1993).

440 53. Eramian, D. et al. A composite score for predicting errors in protein structure models.

$441 \quad$ Protein Sci 15, 1653-1666 (2006).

442 54. Ramachandran, G. N., Ramakrishnan, C. \& Sasisekharan, V. Stereochemistry of 443 polypeptide chain configurations. J Mol Biol 7, 95-99 (1963).

444 55. Kern, D. M. et al. Cryo-EM structure of SARS-CoV-2 ORF3a in lipid nanodiscs. Nat $445 \quad$ Struct Mol Biol 28, 573-582 (2021).

446 56. Humphrey, W., Dalke, A. \& Schulten, K. VMD: visual molecular dynamics. J Mol $447 \quad$ Graph 14, 33-38, 27-28 (1996). 
450 We acknowledge John A. Crump, Jenny G.H. Low, Venance P. Maro, Eng Eong Ooi, and

451 Matt P. Rubach, for contributing patient specimens from which 229E viruses were isolated.

452 We thank Edward C. Holmes and Raoul J de Groot for helpful comments and discussions.

454 Funding

455 This study was supported by the Duke-NUS Signature Research Programme funded by the

456 Ministry of Health, Singapore, and grant NMRC/BNIG/2005/2013 from the National

457 Medical Research Council. M.G.M. and D.H.W.L. are supported by the Integrative Sciences

458 \& Engineering Programme, NUS Graduate School, Singapore. F.S. and P.J.B were supported 459 by BII (A*STAR) core funds.

460

\section{Author contributions}

462 ML and GJDS designed and supervised the research. ML, MGM, DHWL and ZY conducted 463 experiments and performed genome sequencing. MGM, JJ and FYW performed genome assembly and annotation. ML, MGM, JJ, FYW, IHM, YCFS and GJDS performed the and GJDS wrote the paper. All authors took part in data interpretation and edited the paper.

\section{Competing interests}

470 The authors declare no conflicts of interest. 
a
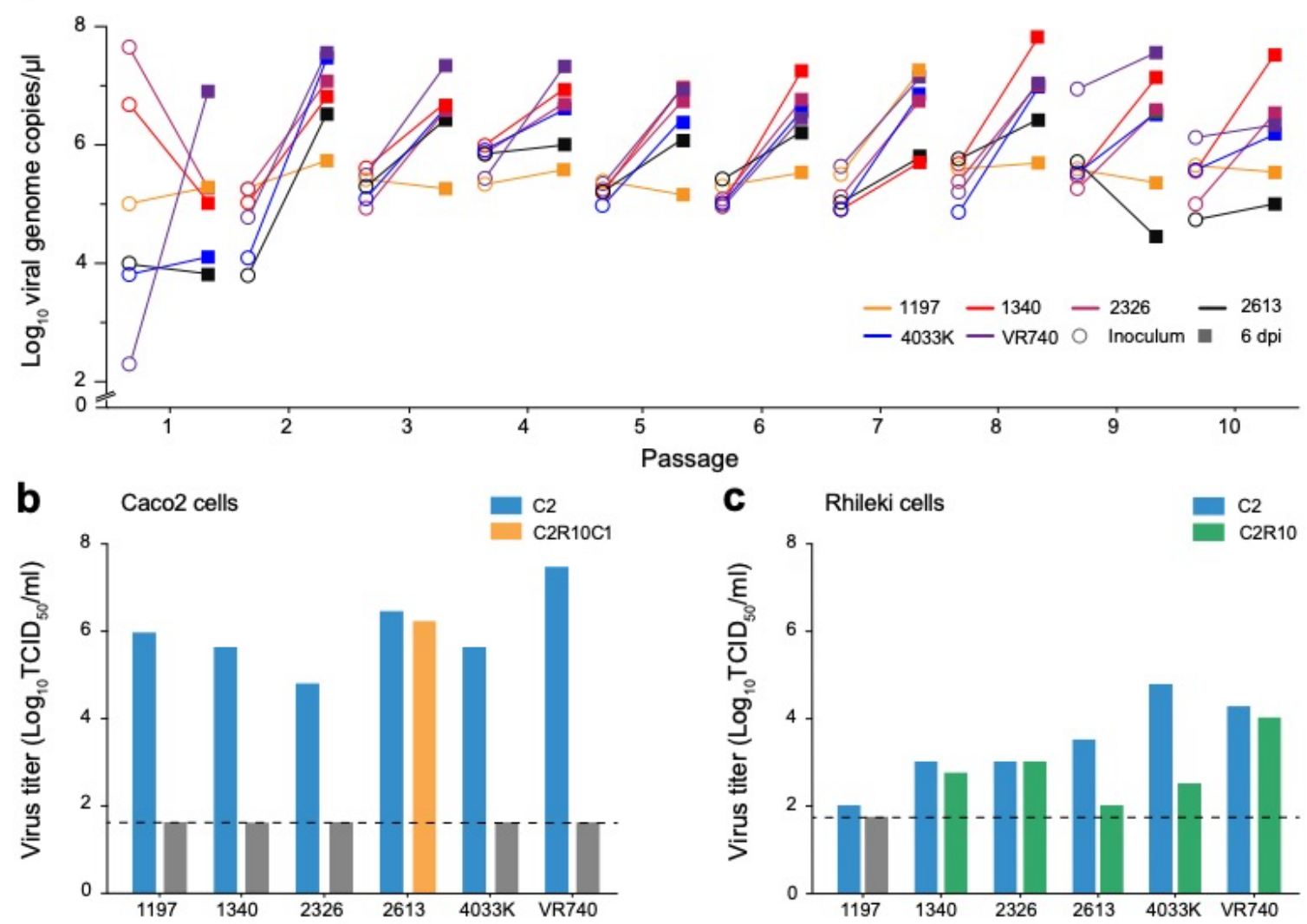

472

473 Fig. 1. Rhileki cells are susceptible and permissive to 229E. a, Rhileki cells were

474 inoculated with six 229E isolates at MOI $=0.01$ and incubated for 6 days. Viral genome

475 copies of the inoculum (circles) and at 6 days post inoculation (square) are plotted. The

476 inoculum for subsequent passages was standardized based on copy number. $\mathbf{b}$, Viral titers

477 (TCID $50 / \mathrm{ml})$ of C2, C2R10 and C2R10C1 viruses titrated in Caco2 cells. c, Viral titers of C2

478 and C2R10 viruses titrated in Rhileki cells. Black dashed lines represent the limit of detection. 


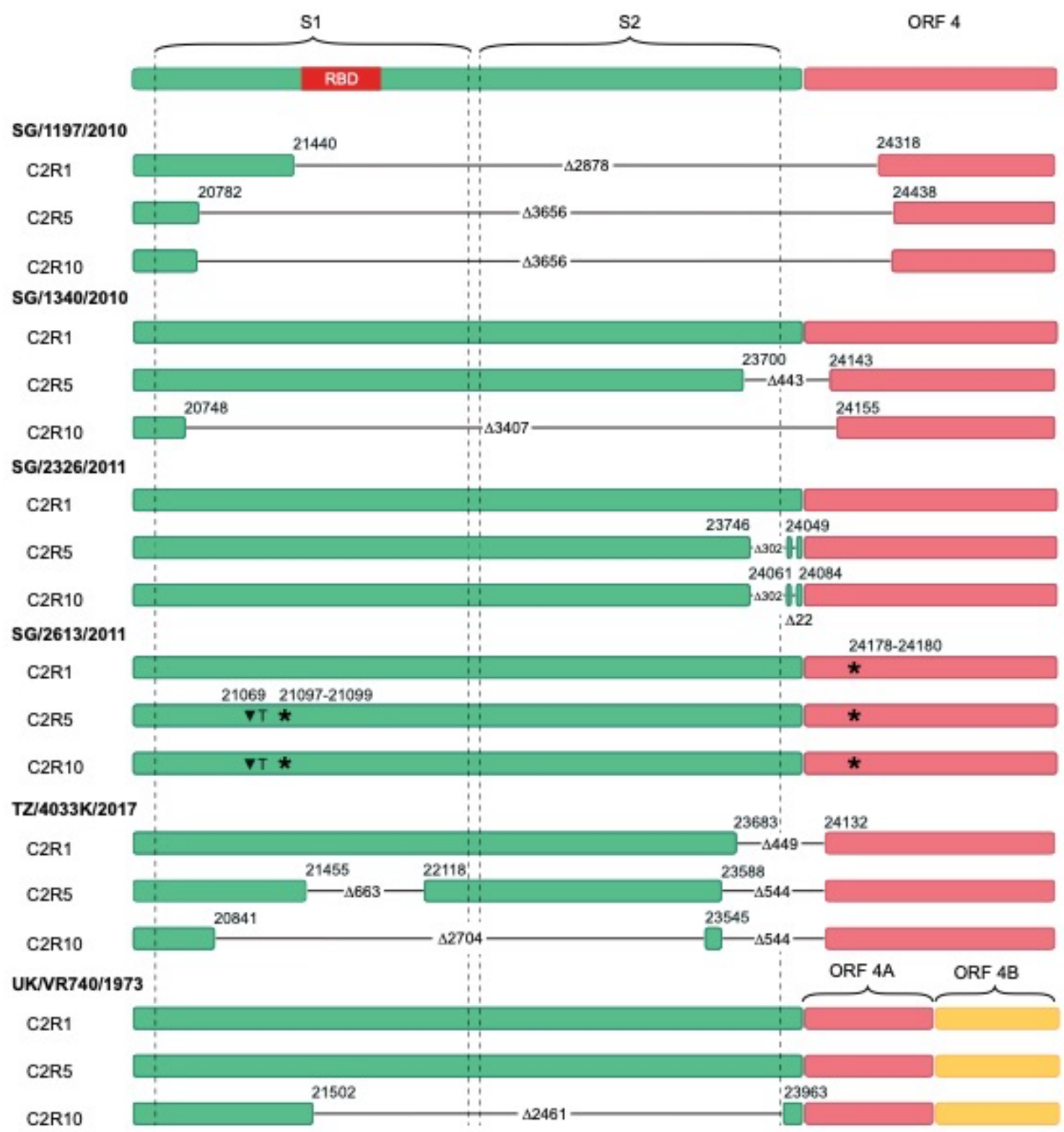

483 229E isolates at passages 1,5 , and 10 in Rhileki cells. Set of filled rectangles atop the

484 figure is a genome schematic representing nucleotides within the spike and ORF 4 genes.

485 RBD indicates the receptor-binding domain. Subsequent filled rectangles represent the

486 genomes of different isolates present at the indicated passages, horizontal black lines indicate

487 deleted parts of the genome with the respective size indicated by a $\Delta$ sign, and starts and ends

488 of the deletions by nucleotide positions situated on top of the rectangles. 

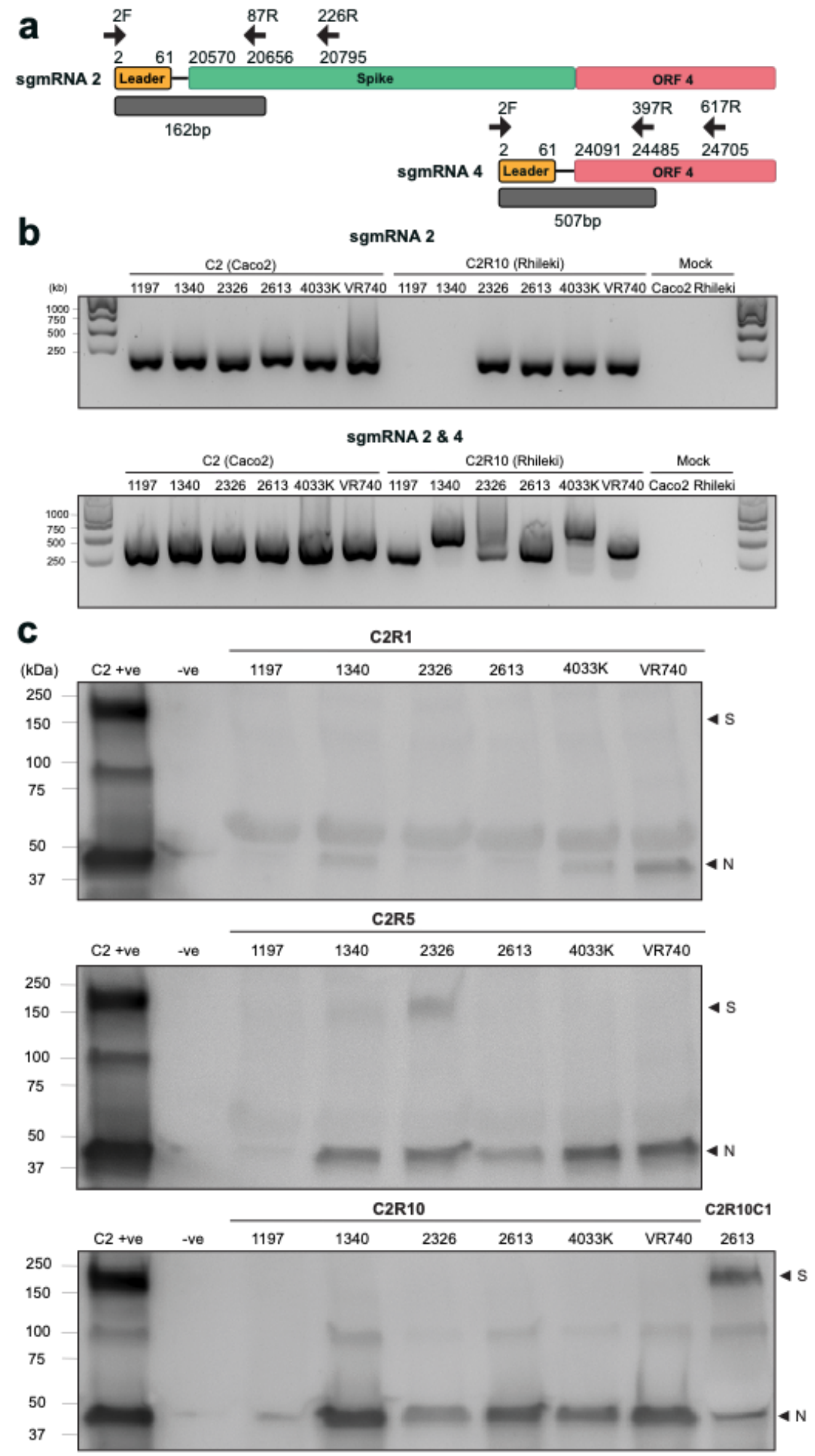
Fig. 3. Sanger sequencing analysis of leader-body junction of sgmRNA 2 and 4. a,

491 Schematic of the leader-body junction of sgmRNA 2 and 4 layered with primer design

492 strategy, nucleotide positions and expected sizes of products C2 and C2R10 viruses. b, Gel

493 image of PCR products after amplification of sgmRNA 2 with primers $2 \mathrm{~F}, 87 \mathrm{R}$ and 226R

494 shown in panel A. Sequencing of PCR products confirmed the presence or absence of the

495 canonical leader-body junction of sgmRNA 2 (162 bp). Gel image of PCR products after

496 amplification of sgmRNA 2 and 4 with primers 2F, 397R and 617R shown in panel A.

497 Sequencing of PCR products confirmed the presence of either the sgmRNA 4 (507 bp) or

498 sgmRNA 2 canonical leader-body junction. c, Western blots of culture supernatants from

499 viruses at passage 1, 5 and 10 on Rhileki cells incubated with 229E anti-spike (S) and anti-

500 nucleoprotein $(\mathrm{N})$. 
a

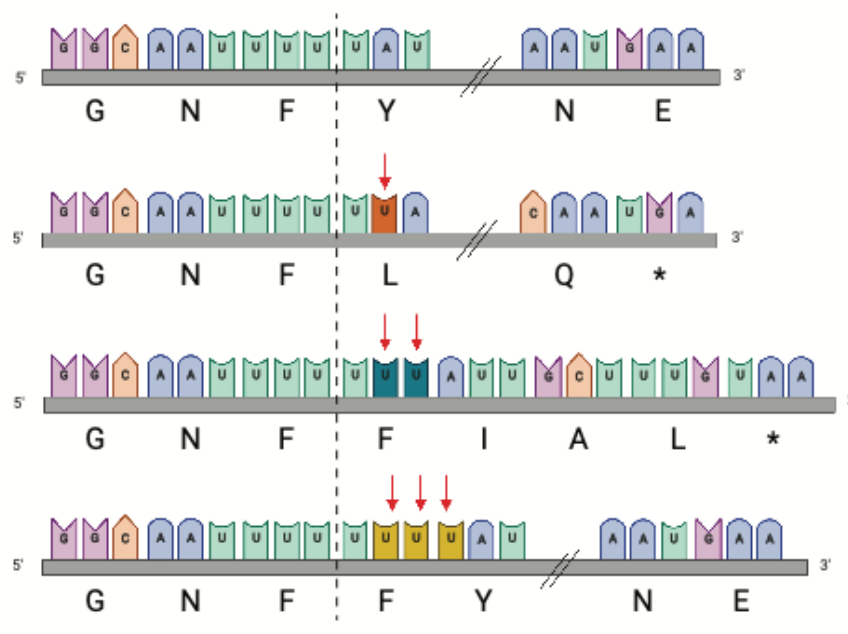

b

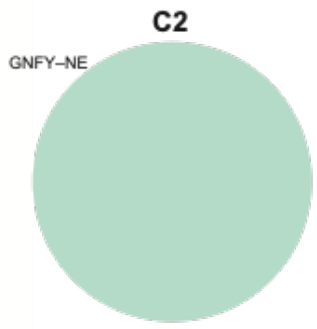

C2R10

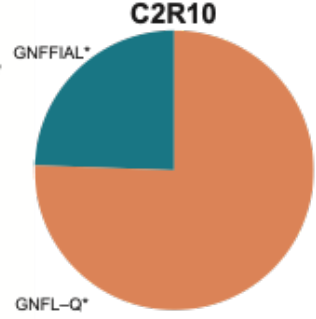

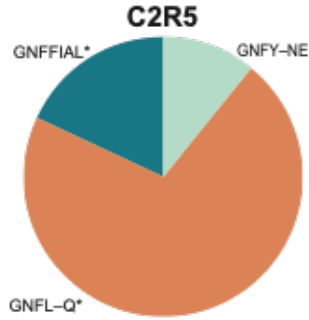

C2R10C1

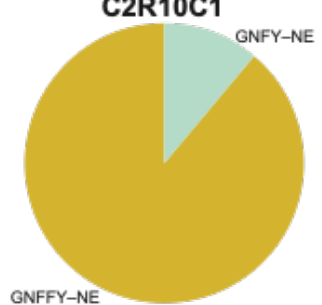

502 Fig. 4. Genetic diversity of SG/2613/2011 spike gene across passages. a, Nucleotide

sequences from position 21,059-21,100 and the corresponding amino acid translation within the S1 domain of the spike gene. Within this region wild type amino acid translation (turquoise) is GNFY-NE. Depending on the passage of the virus, the diversity is comprised of one to three uracil insertions at nucleotide position 21,064 that alter the reading frame. With one (orange) or two (dark green) uracil insertions the reading frame shifts leading to an early stop codon GNFL-Q* (E177*) and GNFFIAL* (L171*), respectively. At three

509 (mustard) uracil insertions, the reading frame remains in-frame but with an additional

510 phenylalanine GNFFY-NE. Double forward slash (//) indicates 8 amino acid residues not

511 shown for clarity of presentation. b, Using next-generation sequencing data, pie charts

512 describes the composition of uracil insertions for $\mathrm{C} 2(100 \%$ no insertions, $\mathrm{n}=8,268), \mathrm{C} 2 \mathrm{R} 5$

513 (11.1\% no insertions; $70.9 \%$ single insertion; $18 \%$ double insertion, $n=323)$ C2R10 (75.8\%

514 single insertion; $24.2 \%$ double insertion, $\mathrm{n}=33)$, and $\mathrm{C} 2 \mathrm{R} 10 \mathrm{C} 1(11.2 \%$ no insertions; $88.8 \%$

515 triple insertion, $\mathrm{n}=347$ ) viruses. 


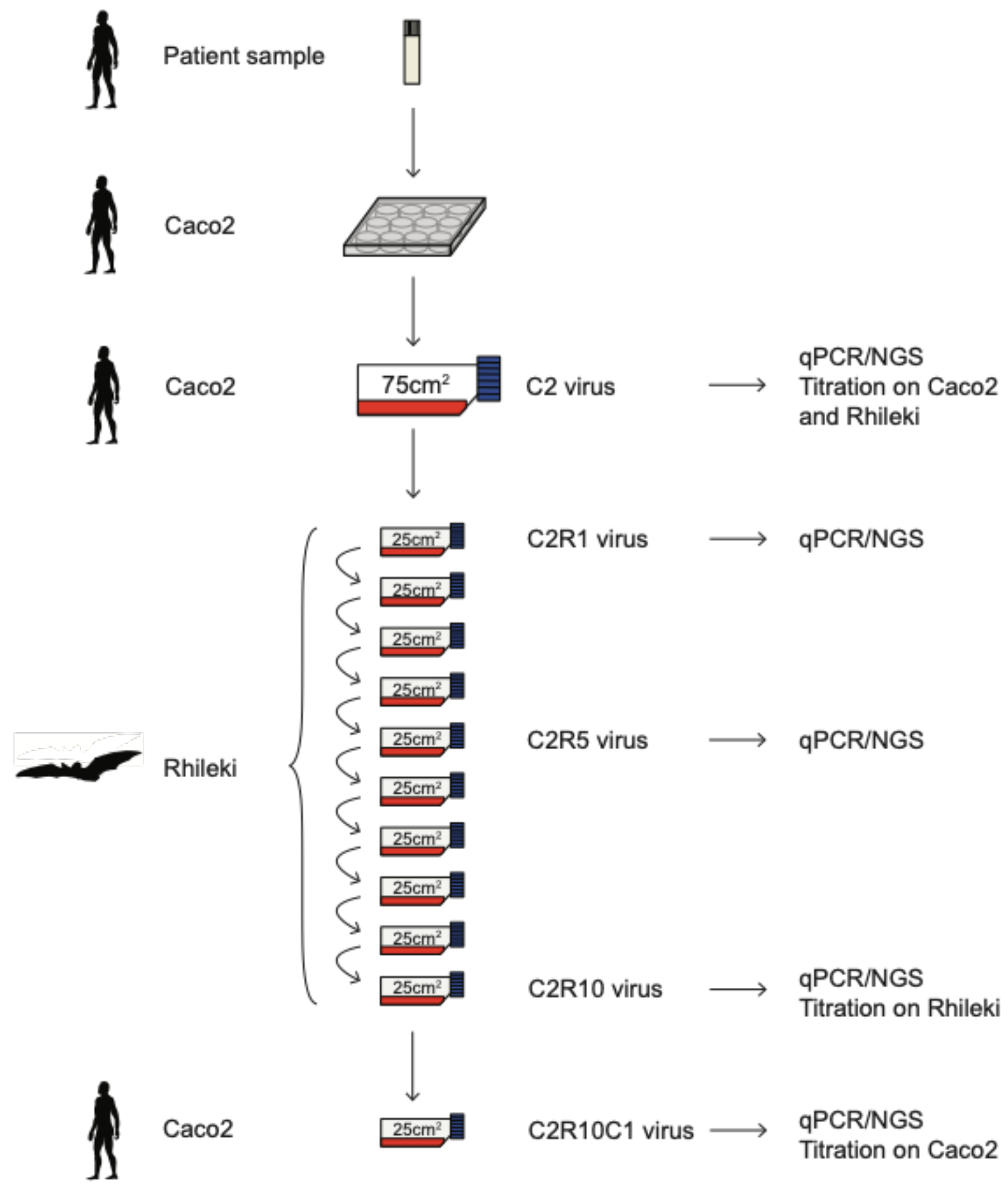

Supplementary Figure 1. Schematic of virus passage experiments. Succession of the virus cultures in our study, nomenclature of viruses, and tests performed on individual batches. 
a

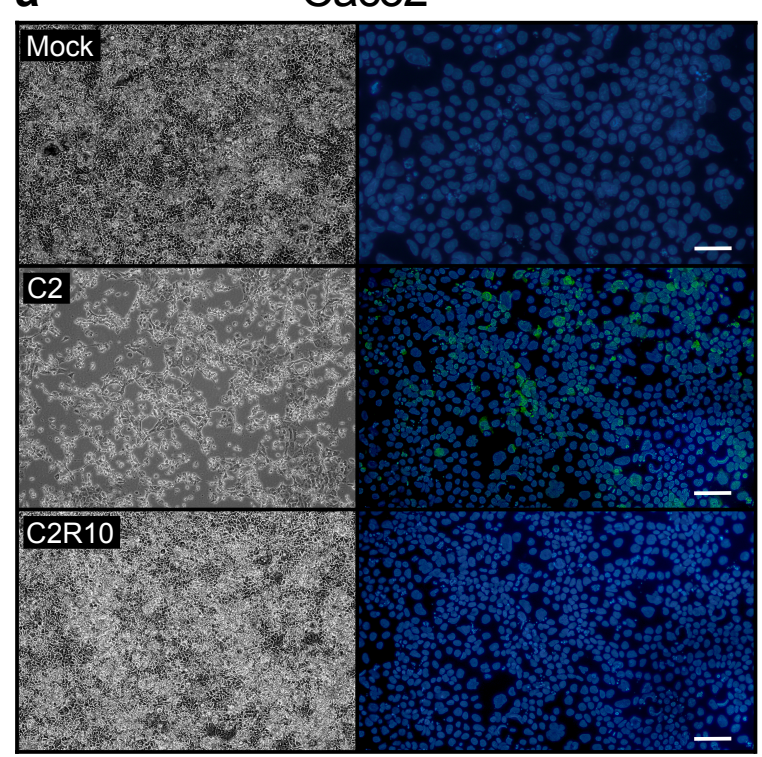

b

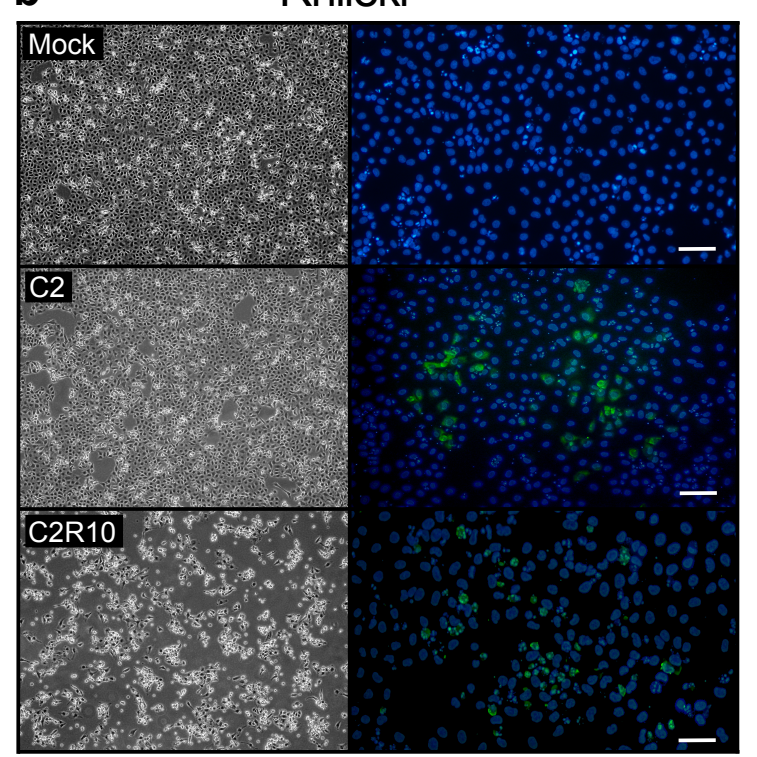

Supplementary Figure 2. Microscopy and immunofluorescence of Caco2 and Rhileki cells infected with $\mathbf{C 2}$ or C2R10 viruses. a, Bright light and immunofluorescence microscopy of Caco 2 cells infected with mock, C2, and C2R10 virus. b, Bright light and immunofluorescence microscopy of Rhileki cells infected with mock, C2, and C2R10 virus. 229E viral nucleocapsid staining (green) and nuclear staining (blue). White scale bar corresponds to $100 \mu \mathrm{m}$. 


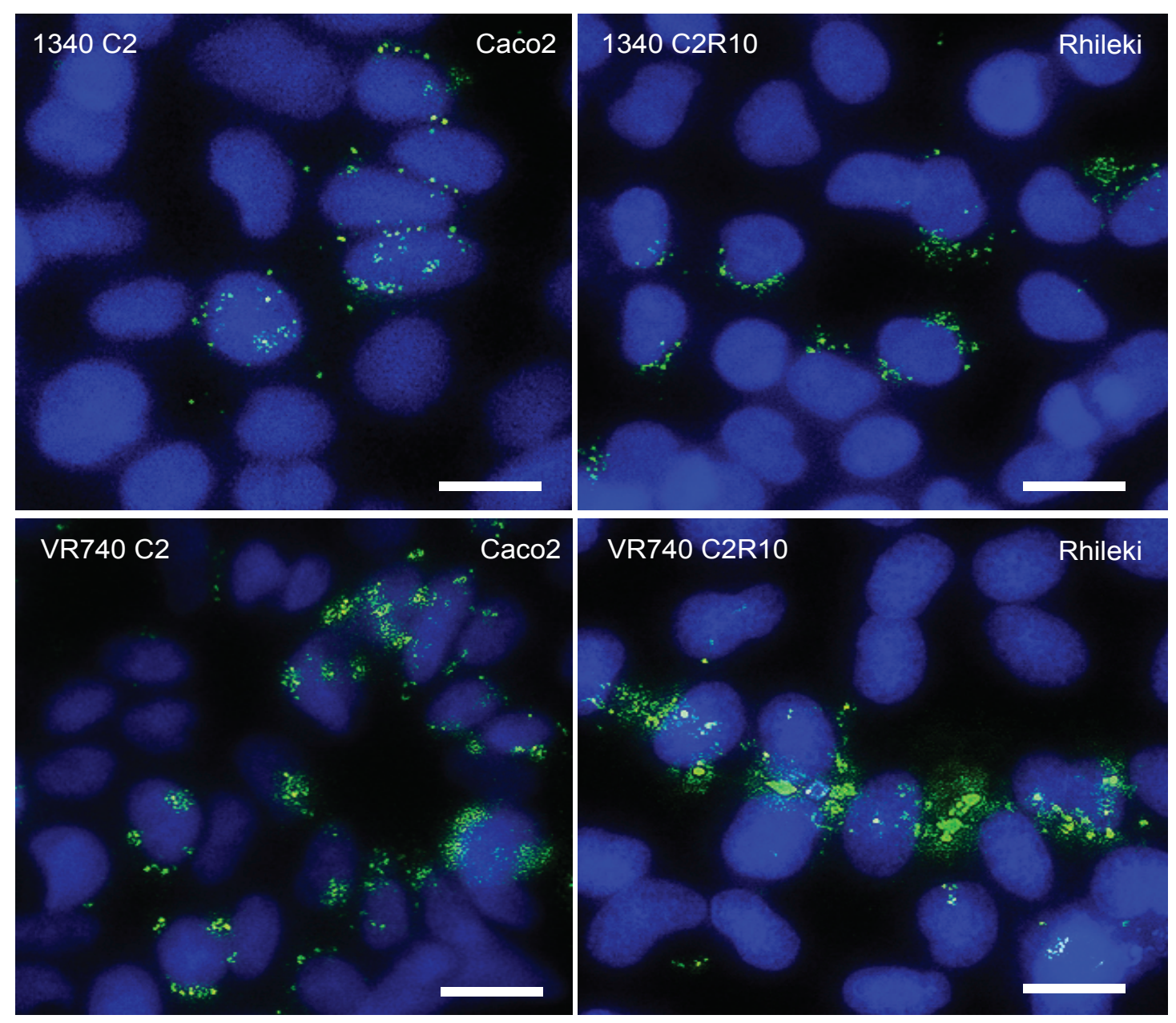

Supplementary Figure 3. Double-stranded RNA staining of Caco2 and Rhileki cells.

Representative images of Caco2 cells infected with $\mathrm{C} 2$ viruses and Rhileki cells infected with C2R10 viruses. Double-stranded RNA intermediates (green) and nuclear staining (blue) visualized at 1 day post inoculation. White scale bar corresponds to $20 \mu \mathrm{m}$. 

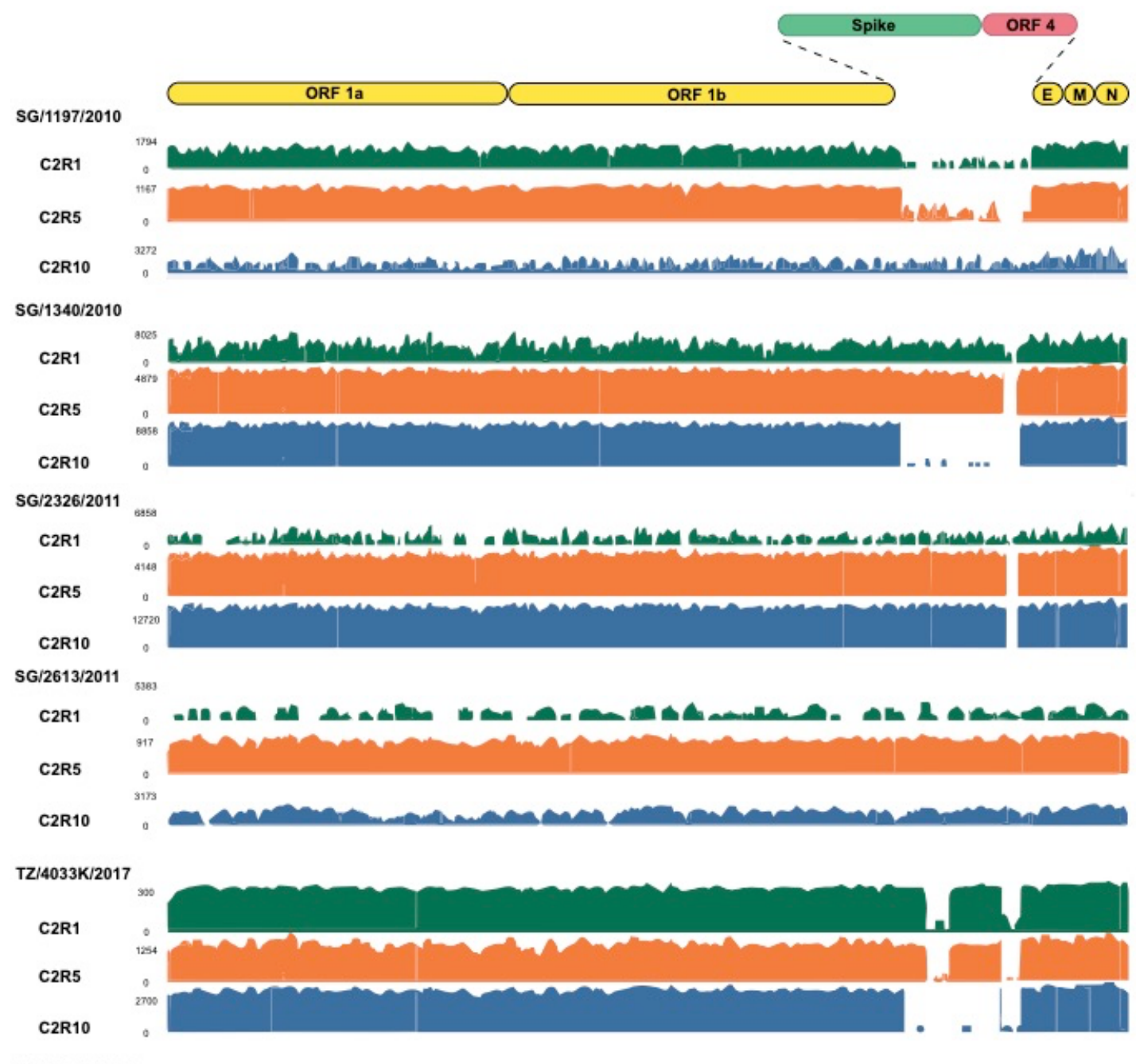

UKNR740/1973

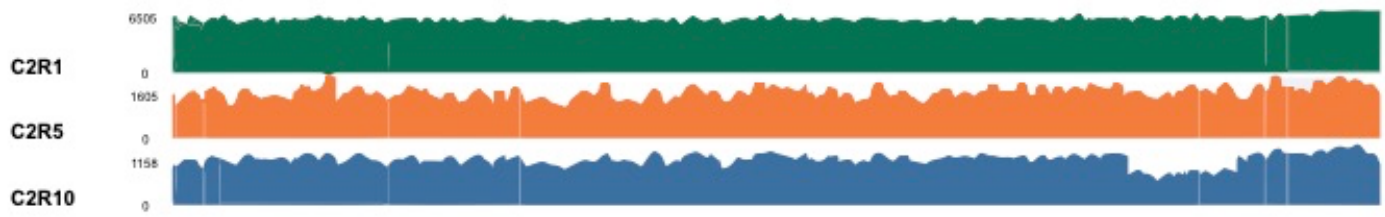

Supplementary Figure 4. Next-generation sequencing. Schematic on top of figure

correspond to the location of the reads situated on the full genome. Coverage spanning the full genome for all six viruses passaged in Rhileki cells, quantified at C2R1, C2R5, and C2R10. 

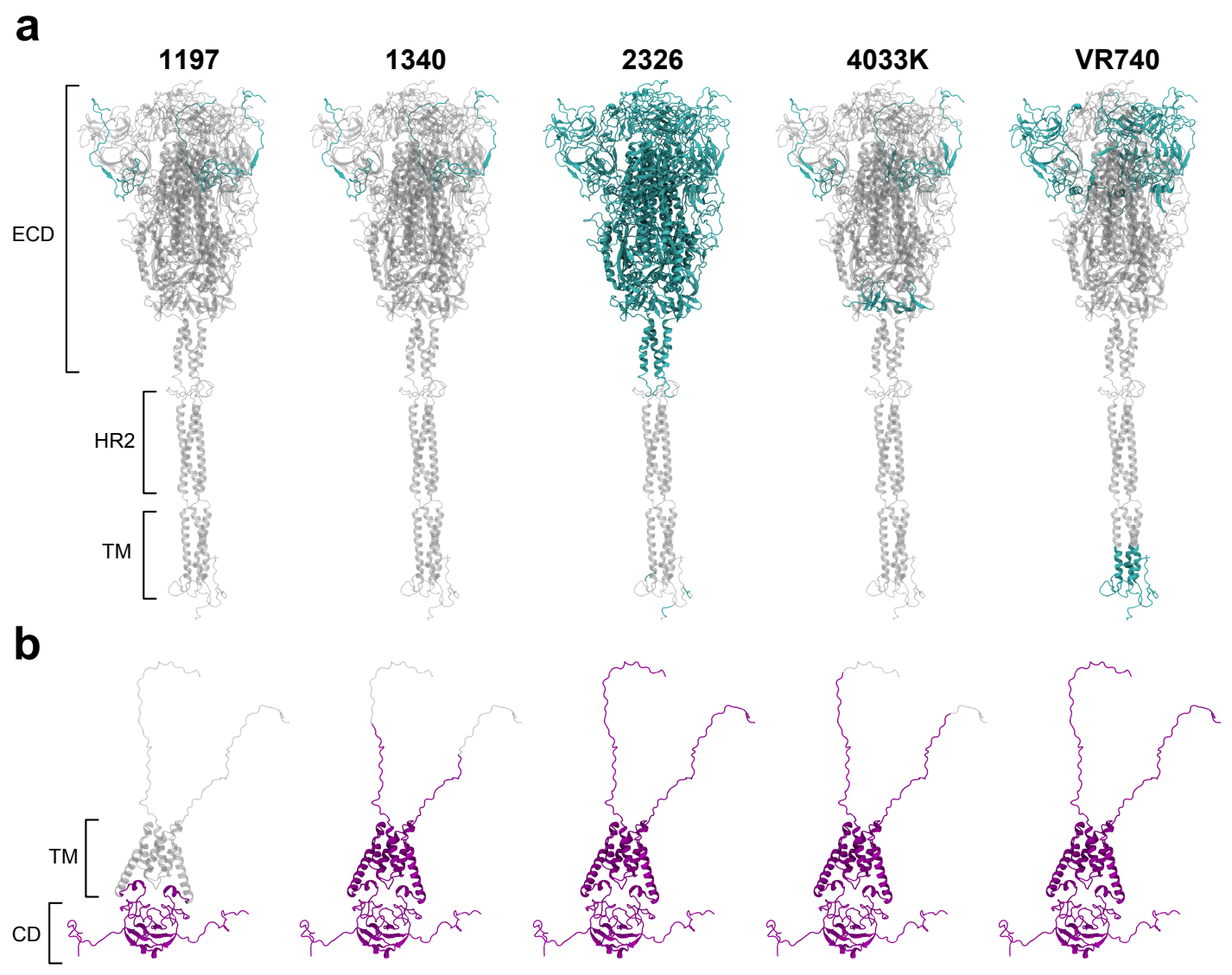

\section{Supplementary Figure 5. Modelling of deleted regions of the spike and ORF4 proteins}

of C2R10. a, Full-length model of 229E S protein built using SARS-CoV-2 S protein as a structural template. The model is shown in cartoon representation, with the deleted regions coloured in grey, and remaining S protein in cyan. b, Full-length model of ORF4 protein, built using the cryo-EM structure of the SARS-CoV-2 ORF3a ion channel (PDB: 7KJR).

Deleted regions are shown in grey and the remaining protein shown in purple. Domains are labelled as ECD (ectodomain), HR2 (heptad repeat 2 domain), TM (transmembrane domain), and CD (cytoplasmic domain). 
a

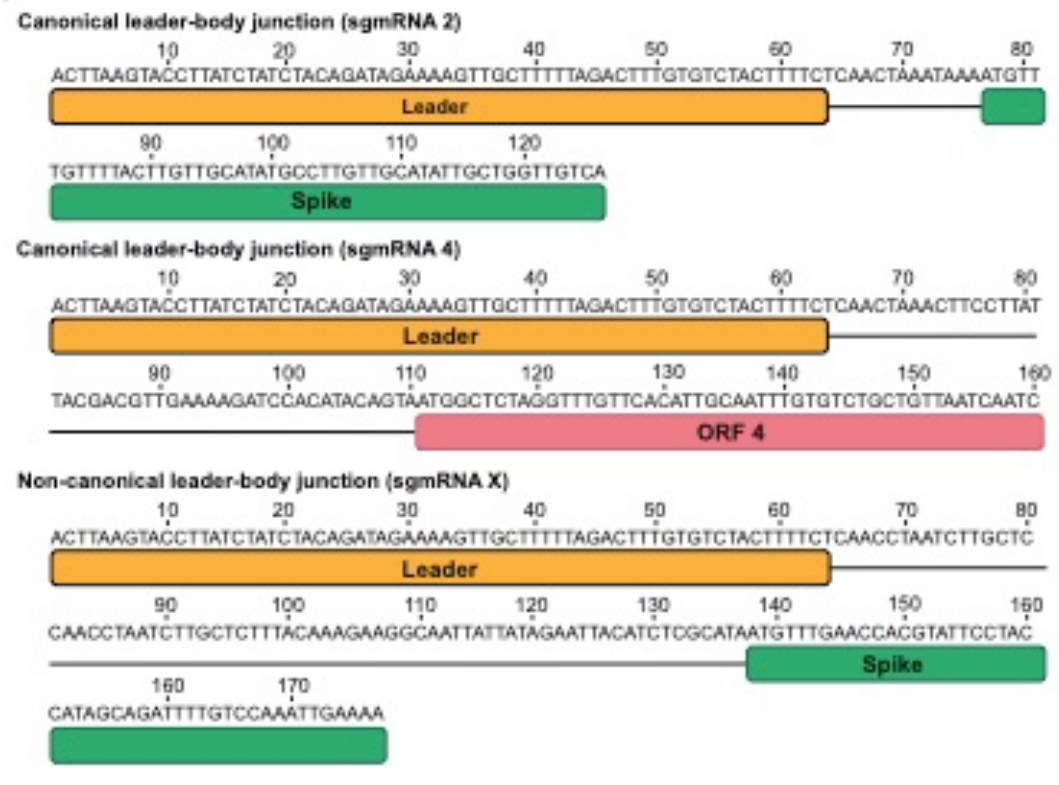

b

sgmRNA 2

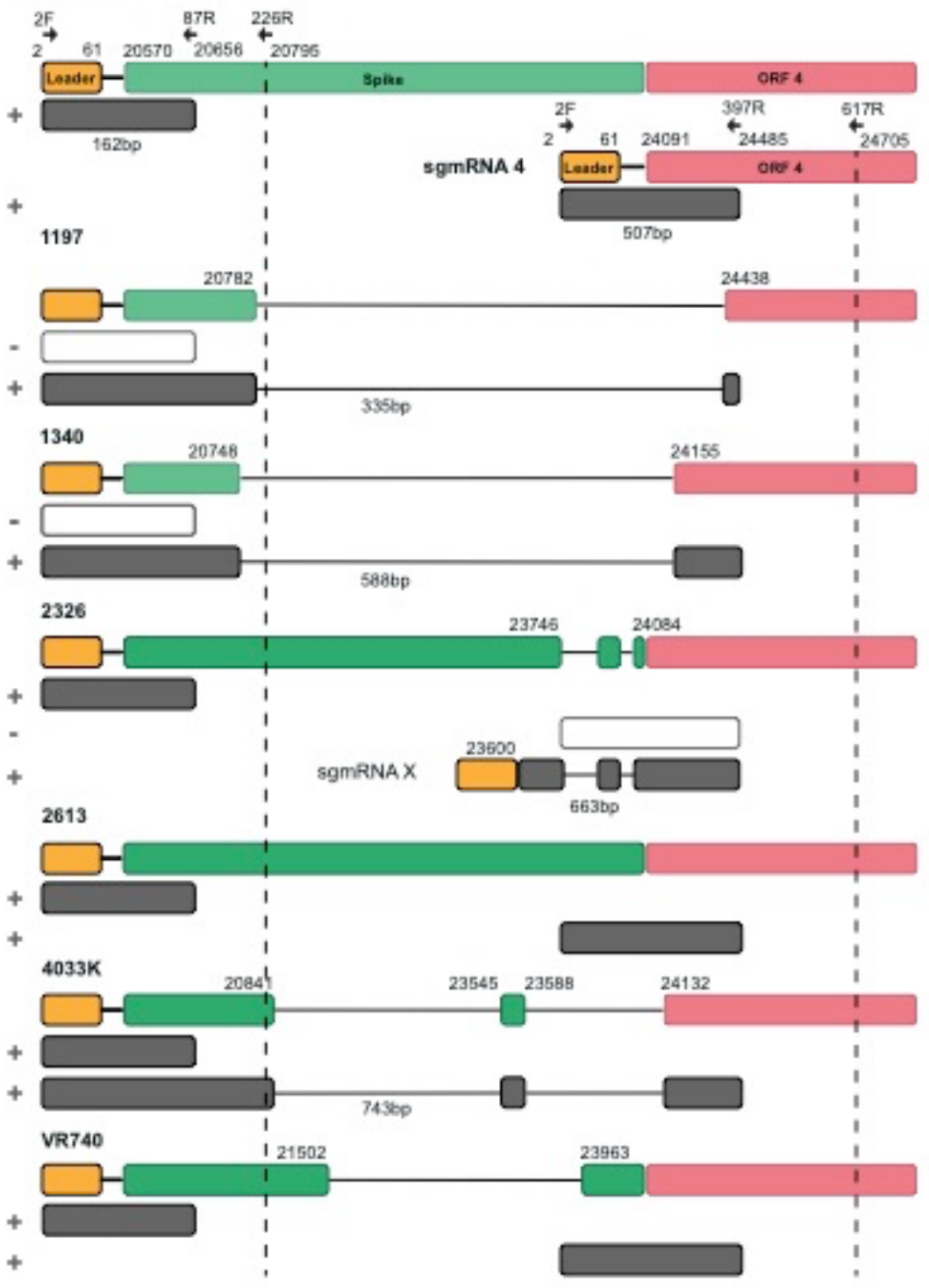




\section{Supplementary Figure 6. Strategy to detect 229E subgenomic mRNA 2 and 4. a,}

Confirmation of the gel bands presented in Fig. 3a by Sanger sequencing show three leaderbody junctions (LBJ) present, canonical LBJ of sgmRNA 2 (spike), canonical LBJ of sgmRNA 4 (ORF4), and non-canonical LBJ (putatively named sgmRNA X) observed only for SG/2326/2011. b, Schematic that explains the primer strategy and size explanation of the bands seen in Fig. 3a. 
Supplementary Table 1. Primers used in this study.

\begin{tabular}{|c|c|c|c|}
\hline Name & Directionality & Sequence & Usage \\
\hline 1197 P5 Del F & Forward & CGGCTGTGTTGGTCATTCG & Deletion verification \\
\hline 1197 P5 Del R & Reverse & GGCTGAGGTCTTTATCAATACG & Deletion verification \\
\hline 1340 P5 Del F & Forward & CGTATTCCTACCATAGC & Deletion verification \\
\hline 1340 P5 Del R & Reverse & AGATCTGCCACGGTGTGATC & Deletion verification \\
\hline 2326 P5 Del F & Forward & GCTCTGAGTTGCAAACTATTGTGC & Deletion verification \\
\hline 2326 P5 Del R & Reverse & CGTGAAACTTCAGCACTAAC & Deletion verification \\
\hline T140 P5 Del F & Forward & CTTGTTAGGAGTGGTAAGTTGC & Deletion verification \\
\hline T140 P5 Del R & Reverse & GCAAGTTGAAGGTAACAGTGCC & Deletion verification \\
\hline T140 P10 Del F & Forward & GCATATGCCTTGTTGCATATTGC & Deletion verification \\
\hline T140 P10 Del R & Reverse & CGCTAGCAAGTTGAAGGTAACAGTGC & Deletion verification \\
\hline T140 Del 1 R & Reverse & GCACAACCCAGACCACG & Deletion verification \\
\hline T4033 P5 Del F & Forward & CTCCATACTGTCTTGCTGC & Deletion verification \\
\hline T4033 P5 Del R & Reverse & GCAGATCTGCCACGGTGTGAT & Deletion verification \\
\hline T4033 P10 Del F & Forward & GGTTATATACCCTCCAACTTTGC & Deletion verification \\
\hline T4033 P1-1Del F & Forward & AGACTGAGATGTGACCAGC & Deletion verification \\
\hline T4033 P1-2Del F & Forward & TTCGTGCTTCCAGACAGCTTGC & Deletion verification \\
\hline T4033 P1-1Del R & Reverse & GCATGGCGCTATTTCTTAAGGC & Deletion verification \\
\hline T4033 P10Del2 F & Forward & CGCATAATGTTTGAACCACG & Deletion verification \\
\hline $2 \mathrm{~F}$ & Forward & CTTAAGTACCTTATCTATCTACAGATA & sgmRNA $2 / 4$ PCR $1 / 2$ \\
\hline $226 \mathrm{R}$ & Reverse & GCTGAAAACTCCTCACAACACC & sgmRNA 2 cDNA \\
\hline $158 \mathrm{R}$ & Reverse & GCAAAGTTGGAGGGTATATAACC & sgmRNA 2 PCR 1 \\
\hline $87 \mathrm{R}$ & Reverse & GCAAACAGAGTGACTAGTGTTCGTC & sgmRNA 2 PCR 2 \\
\hline $617 \mathrm{R}$ & Reverse & GCTGGGTGTTCACAAAACAAGTATA & sgmRNA 4 cDNA \\
\hline $520 \mathrm{R}$ & Reverse & CGTACAAATCGTTAGTTGAGAG & sgmRNA 4 PCR 1 \\
\hline 397R & Reverse & GCACATAGCAAAGTGTGGTTAC & sgmRNA 4 PCR 2 \\
\hline
\end{tabular}


Supplementary Table 2. Synonymous and non-synonymous mutations in virus from passages 1, 5, and 10.

\begin{tabular}{|c|c|c|c|c|c|c|c|c|}
\hline Isolate & Gene & Nucleotide mutation & Amino acid mutation & Mutation & $\mathrm{C2}$ & C2-R1 & C2-R5 & C2R10 \\
\hline \multirow[t]{2}{*}{ SG/1340/2010 } & NSP3 & A4854G & D621G & Non-synonymous & $\mathrm{D}$ & $100 \% \mathrm{D}$ & $65.5 \% \mathrm{G}$ & $100 \% \mathrm{G}$ \\
\hline & NSP10 & $\mathrm{C} 12249 \mathrm{~T}$ & T46I & Non-synonymous & $\mathrm{T}$ & $47 \% \mathrm{~T}$ & $64.0 \% \mathrm{I}$ & $100 \% \mathrm{I}$ \\
\hline \multirow[t]{3}{*}{$\mathrm{SG} / 2326 / 2011$} & NSP3 & A4854G & D621G & Non-synonymous & $\mathrm{D}$ & $100 \% \mathrm{D}$ & $100 \% \mathrm{D}$ & $100 \% \mathrm{G}$ \\
\hline & NSP15 & T19179G & - & Synonymous & $\mathrm{T}$ & $100 \% \mathrm{G}$ & $95.0 \% \mathrm{G}$ & $100 \% \mathrm{G}$ \\
\hline & Membrane & $\mathrm{T} 25258 \mathrm{C}$ & F81L & Non-synonymous & $\mathrm{F}$ & $100 \% \mathrm{~F}$ & $100 \% \mathrm{~F}$ & $100 \% \mathrm{~L}$ \\
\hline \multirow[t]{4}{*}{$\mathrm{SG} / 2613 / 2011$} & NSP8 & $\mathrm{C} 11462 \mathrm{~T}$ & H88Y & Non-synonymous & $\mathrm{H}$ & $100 \% \mathrm{Y}$ & $100 \% \mathrm{Y}$ & $100 \% \mathrm{Y}$ \\
\hline & Spike & $\mathrm{C} 20603 \mathrm{~T}$ & L5F & Non-synonymous & $\mathrm{L}$ & $100 \% \mathrm{~L}$ & $100 \% \mathrm{~F}$ & $100 \% \mathrm{~F}$ \\
\hline & ORF4 & $\mathrm{C} 24200 \mathrm{~T}$ & Q30* & Non-synonymous & Q & $100 \% *$ & $100 \% *$ & $100 \% *$ \\
\hline & ORF4 & G24423T & G104V & Non-synonymous & G & $100 \% \mathrm{G}$ & $96.0 \% \mathrm{G}$ & $100 \% \mathrm{~V}$ \\
\hline \multirow[t]{4}{*}{$\mathrm{TZ} / 4033 \mathrm{~K} / 2017$} & NSP2 & $\mathrm{C} 2954 \mathrm{~T}$ & - & Synonymous & $\mathrm{C}$ & $100 \% \mathrm{~T}$ & $100 \% \mathrm{~T}$ & $100 \% \mathrm{~T}$ \\
\hline & NSP3 & $\mathrm{C} 7074 \mathrm{~T}$ & $\mathrm{~S} 1361 \mathrm{~F}$ & Non-synonymous & $\mathrm{S}$ & $100 \% \mathrm{~F}$ & $100 \% \mathrm{~F}$ & $100 \% \mathrm{~F}$ \\
\hline & Membrane & $\mathrm{C} 25177 \mathrm{~T}$ & L54F & Non-synonymous & $\mathrm{L}$ & $100 \% \mathrm{~L}$ & $100 \% \mathrm{~L}$ & $100 \% \mathrm{~F}$ \\
\hline & Nucleocapsid & $\mathrm{T} 26118 \mathrm{C}$ & V137A & Non-synonymous & $\mathrm{V}$ & $100 \% \mathrm{~V}$ & $97.1 \% \mathrm{~V}$ & $100 \% \mathrm{~A}$ \\
\hline \multirow[t]{4}{*}{ UK/VR740/1973 } & NSP2 & $\mathrm{C} 712 \mathrm{~T}$ & - & Synonymous & $\mathrm{C}$ & $100 \% \mathrm{~T}$ & $72.4 \% \mathrm{~T}$ & $100 \% \mathrm{~T}$ \\
\hline & NSP2 & C1083A & S153Y & Non-synonymous & $\mathrm{S}$ & $100 \% \mathrm{~S}$ & $100 \% \mathrm{~S}$ & $86.9 \% \mathrm{Y}$ \\
\hline & NSP3 & A4907G & $\mathrm{I} 634 \mathrm{~V}$ & Non-synonymous & I & $62.05 \% \mathrm{I}$ & $100 \% \mathrm{~V}$ & $100 \% \mathrm{~V}$ \\
\hline & NSP4 & $\mathrm{T} 7848 \mathrm{C}$ & M28T & Non-synonymous & M & $51.7 \% \mathrm{~T}$ & $100 \% \mathrm{~T}$ & $100 \% \mathrm{~T}$ \\
\hline
\end{tabular}

